\title{
Mental Health of Chinese Peacekeepers in Liberia
}

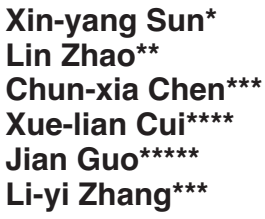

* Department of Psychology and Psychiatry, Second Military Medical University, Shanghai; Prevention and Treatment Center of Psychological Diseases, No. 102 Hospital of Chinese People's Liberation Army, Changzhou, Jiangsu

** Department of Psychiatry, Guangji Hospital, Suzhou, Jiangsu

*** Prevention and Treatment Center of Psychological Diseases, No. 102 Hospital of Chinese People's Liberation Army, Changzhou, Jiangsu

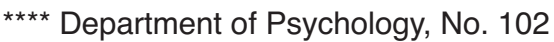
Hospital of Chinese People's Liberation Army, Changzhou, Jiangsu

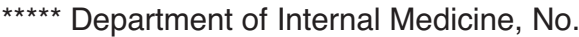
102 Hospital of Chinese People's Liberation Army, Changzhou, Jiangsu

CHINA

ABSTRACT - Background and Objectives: As part of UN peacekeeping operations in Liberia, China has sent a dozen of batches of peacekeeping force to Liberia for medical, engineering and transporting purposes from 2003 to 2012. This study aimed to explore the mental health of Chinese peacekeepers under the influence of stressful and traumatic events in Liberia.

Methods: A total of 440 Chinese peacekeepers were selected by cluster sampling and surveyed by Chinese Military Mental Health Scale (CMMHS) before, during and after peacekeeping deployment.

Results: The total CMMHS score $(48.90 \pm 21.15)$, depression factor $(7.25 \pm 3.43)$, interpersonal sensitivity $(4.20 \pm 2.15)$ of Chinese peacekeepers were significantly higher than the Chinese military norm $(23.04 \pm 14.70,2.47 \pm 2.46,3.95 \pm 2.97$ respectively $)(p<0.01)$. The total score and anxiety, somatization factor score of the transporting group were significantly higher than those of the medical group ( $\mathrm{P}<0.05)$; All CMMHS factors in the transporting group and the medical group were higher than those of the engineering group 
$(\mathrm{p}<0.01)$. CMMHS factors score of the peacekeepers positively correlated with the age, military service duration, years of eudcation and military rank $(r=0.107 \sim 0.523, p<0.05)$; stepwise linear regression analysis revealed that years of eudcation was the main influence factor for peacekeepers' mental health $(\mathrm{t}=2.288 \sim 4.358, \mathrm{p}<0.05 \sim 0.01)$.

Conclusions: The mental health status of Chinese peacekeepers was worse than average Chinese servicemen. Peacekeepers of different mission groups had different degree of mental damage, and the years of education was the main influence factor for peacekeepers' mental health, whereas age, military service duration as well as military rank were the secondary influence factors.

Received: 12 October 2013

Revised: 22 January 2014

Accepted: 5 February 2014

\section{Introduction}

The role of UN peacekeeping operations, or humanitarian intervention, increased dramatically in recent years as global concerns have been drawn to local armed conflicts which greatly threatened global security and severely undermined stability. Peacekeepers constitute a unique population for study in that peacekeeping missions can be extremely stressful and traumatic. Combat-related trauma and subsequent mental illnesses that persist for a long time afterwards ${ }^{1-5}$ have been noted since World War I. The incidence rate of stress-related psychological problems and stress disorder in military personnel is much higher than the general population ${ }^{6,7}$. Chinese military personnel are often subject to emergent and extraordinary military tasks such as earthquake relief, flood relief, crash rescue, terrorism, epidemics, etc., giving rise to psychological stress response and inducing strong psychological conflicts and adverse emotional reactions, mainly in forms of anxiety, depression, somatization disorder, interpersonal sensitivity, obsessive-compulsive paranoia and insomnia ${ }^{8-11}$. Rising up to emerging challenges, China had repeatedly sent military teams to countries in Africa for peacekeeping missions since 2003. Many reports on peacekeeping operations focused upon political and social issues, while the peacekeepers' mental health received less attention ${ }^{12}$. According to some studies, mental health problems contribute greatly to the reasons for committing suicide in peacekeepers ${ }^{3,4}$, thus assessing the mental health status of peacekeepers and dealing timely and properly with mental health problems have become extremely important. Epidemiological studies of soldiers during post-deployment of combating events and peacekeeping missions have demonstrated a high prevalence of mental disorders, mental health service use, and somatic complaints $^{2,3,13}$. Jitender et al. investigated mental disorders, suicidal ideation, self-perceived need for treatment, and mental health service utilization attributable to exposure to peacekeeping and combat operations among Canadian military personnel, and found that a substantial proportion, but not the majority, of mental health-related outcomes were attributable to combat or peacekeeping deployment ${ }^{14}$. Carol et al. investigated the psychological impact of peacekeeping duties on $277 \mathrm{New}$ Zealand Defense Force personnel, and found that peacekeeping duty did impact upon the mental health status of the personnel in- 
volved $^{15}$. China started taking on its peacekeeping role as part of UN peacekeeping missions since December 2003. There had been 14 batches sent to Liberia as of July 2013 with an average batch of 600 military personnel. The peacekeeping operation for each batch would last about eight months. When the eight months was over, another batch would take over. By far, the few studies about mental health of the peacekeepers were confined to a unit or a particular aspect of psychological problems. This study aimed to explore the mental health status of Chinese peacekeepers under the influence of stressful and traumatic events in Liberia, in an effort to provide valuable references and scientific evidences for mental disorder prevention and psychological intervention.

Table 1

Demographic characteristics of participants $(n=440)$

\begin{tabular}{ll} 
Variables & Mean (SD) or N (\%) \\
\hline Age (years) & $26.36(4.22)$ \\
Married or partnered & $98(22.3 \%)$ \\
Education(years) & $12.71(1.69)$ \\
Ranks & \\
$\quad$ Officers & $85(19.3 \%)$ \\
$\quad$ Soldiers & $355(80.7 \%)$ \\
Mission groups & $205(41.8 \%)$ \\
$\quad$ Engineering group & $39(9.7 \%)$ \\
$\quad$ Medical group & $169(48.5 \%)$ \\
$\quad$ Transporting group & $8.27(4.23)$ \\
Service duration &
\end{tabular}

\section{Methods}

\section{Participants}

Between December 2003 and November 2005 , there had been altogether three batches, about 1811 military personnel in total, sent to
Liberia. A total of 440 Chinese peacekeepers were selected by systematic random sampling from the 1811 military personnel to participate in this study. Their demographic variables are shown in Table 1. All the participants reported no mental illness, no history of drug abuse or alcohol dependence.

\section{Material}

The Chinese version of the Chinese Military Mental Health Scale (CMMHS) ${ }^{16}$ was used to assess mental health status of Chinese peacekeepers in Liberia. SCL-90 and EPQ are usually used to assess mental health status for civilian purpose, but inappropriate for military purpose taking into consideration the special military environment and the exceptional nature of military activities. CMMHS was developed by the People's Liberation Army Prevention and Treatment Centre of Psychological Diseases, consisting of 98 items in 9 factors, namely obsession, anxiety, depression, horror, psychosis, neurasthenia, interpersonal sensitivity, somatization and a lying factor. It is dichotomously scored with yes scoring 0 and no scoring 1 . Higher score indicated worse mental health status and higher risks of mental disorders. Its reliability and validity have been verified by a series of tests among new military recruits. Its internal consistency reliability reached 0.88 , and the test-retest reliability was over 0.80 . The cumulative contribution of its nine factors exceeded $70 \%$, indicating good construct validity of this scale. Its criterion validity against SCL-90 proved to be excellent and predictive validity also turned out to be great by repeated verifying tests among new recruits in recent years ${ }^{17}$. Its screening sensitivity is as high as $91.9 \%$ and specificity is $95.1 \%$. In addition, the military norm of mental health established by this identical institution (People's Liberation Army Prevention 
and Treatment Centre of Psychological Diseases) with a huge sample of 8002 servicemen was used as the baseline level in this study ${ }^{18}$.

\section{Procedure}

Before the deployment, a short-term training class was given to all the participants involved in this study with the aim of explaining the purpose of the study and obtaining their written informed consents. By group testing method, all participants were tested by CMMHS before, during (4 months into the deployment) and after the peacekeeping deployment. The participants were required to fill out the forms with general information, including age, military service duration, years of education, marital status, mission groups and so on, without being required to fill out their names. If the score of lying factor was higher than 66(military norm), then the scale report was considered as invalid data and would not be used in the statistical analysis. By systematic random sampling, a total of 452 servicemen were selected from the 1811 military personnel to participant in this study, and 12 reports of the 452 participants were removed from the final data as invalid, making a validity rate $97.35 \%$.

\section{Data analysis}

All data was analyzed by using the SPSS version 12.0. The frequencies of demographics were first obtained and compared using the independent sample $t$ test and chi-squared test to evaluate the homogeneity of the groups; matched pair $t$ test was then performed to compare mental status of the peacekeepers before, during and after deployment; ANOVA analysis and LSD analysis were performed to investigate the differences of CMMHS total score and factors score among and between the three groups; stepwise linear regression analysis was used to determine the main in- fluence factors of the peacekeepers' mental health during Liberia deployment.

\section{Results}

As Table 2 shows, there were no significant differences $(\mathrm{p}>0.05)$ in the total score and factors score of the CMMHS before, during and after the deployment. However, the total score and factors score for peacekeepers were significantly higher than those of average Chinese servicemen $(\mathrm{p}<0.01)$.

Repeated measures design analysis of variance showed that there were significant differences in three groups who participated in the peacekeeping mission, as showed in Table 3. Compared with the engineering group, the transporting group and medical group had significantly higher total and factors score of the CMMHS before and after the deployment $(\mathrm{p}<0.01)$. The transporting group showed significantly higher somatization score than that of medical group before the deployment $(\mathrm{p}<0.01)$; while the medical group showed significantly higher total score and anxiety factor score than those of transporting group after the deployment $(\mathrm{p}<0.01)$.

Spearman correlation analysis showed that age, military service duration, years of education, mission groups positively correlated with CMMHS factor scores $(\mathrm{p}<0.01 \sim 0.05$ ) as shown in Table 4. In order to eliminate confounders, multi-factor analysis was performed. Taking the factors which affected the mental health of peacekeepers such as age, military service duration, years of education, mission groups and other factors as independent variables, and the total score as well as factors score of the CMMHS as the dependent variables, the multiple regression analysis found that years of education was entered in all regression equations $(\mathrm{t}=2.288$ $\sim 4.358$; $\mathrm{p}<0.05 \sim 0.01$ ). 
Table 2

The total score and factors score of CMMHS before, during and after peacekeeping mission $(\mathrm{M} \pm \mathrm{SD})$

\begin{tabular}{lcccc} 
Items & $\begin{array}{c}\text { Before } \\
(\mathrm{n}=440)\end{array}$ & $\begin{array}{c}\text { During } \\
(\mathrm{n}=440)\end{array}$ & $\begin{array}{c}\text { After } \\
(\mathrm{n}=440)\end{array}$ & $\begin{array}{c}\text { Average Chinese } \\
\text { servicemen } \\
(\mathrm{N}=8002)\end{array}$ \\
\hline Total & $44.35 \pm 18.34 *$ & $44.25 \pm 18.44 *$ & $44.52 \pm 18.58 *$ & $23.04 \pm 14.70$ \\
Compulsiveness & $3.09 \pm 1.68 *$ & $3.11 \pm 1.70 *$ & $3.10 \pm 1.72 *$ & $1.15 \pm 1.18$ \\
Anxiety & $6.25 \pm 3.02 *$ & $6.18 \pm 2.98 *$ & $6.18 \pm 2.97 *$ & $3.07 \pm 2.43$ \\
Depression & $7.17 \pm 3.46 *$ & $7.35 \pm 3.44 *$ & $7.25 \pm 3.43 *$ & $2.47 \pm 2.46$ \\
Horror & $4.17 \pm 2.15 *$ & $4.05 \pm 2.11 *$ & $4.12 \pm 2.16 *$ & $2.28 \pm 1.63$ \\
Psychoticism & $9.87 \pm 4.35 *$ & $9.69 \pm 4.43 *$ & $9.79 \pm 4.31 *$ & $3.51 \pm 3.00$ \\
Neurasthenia & $3.59 \pm 1.85 *$ & $3.55 \pm 1.84 *$ & $3.73 \pm 1.81 *$ & $1.87 \pm 1.61$ \\
Somatization & $6.12 \pm 3.00 *$ & $6.17 \pm 2.96 *$ & $6.16 \pm 3.04 *$ & $2.80 \pm 2.37$ \\
Lying & $6.14 \pm 2.95 *$ & $6.24 \pm 2.90 *$ & $6.13 \pm 3.07 *$ & $3.95 \pm 2.97$ \\
Interpersonal sensitivity & $4.08 \pm 2.09 *$ & $4.15 \pm 2.12 *$ & $4.20 \pm 2.15 *$ & $1.93 \pm 1.56$
\end{tabular}

Note. Against the average Chinese servicemen, ${ }^{*} \mathrm{p}<0.01$.

Table 3

Total score and factors score of the CMMHS in different mission groups before and after peacekeeping operation $(\mathrm{M} \pm \mathrm{SD})$

\begin{tabular}{llccc} 
Items & Test time & $\begin{array}{c}\text { Engineering } \\
\text { group }(\mathrm{n}=205)\end{array}$ & $\begin{array}{c}\text { Medical } \\
\text { group }(\mathrm{n}=39)\end{array}$ & $\begin{array}{c}\text { Transporting } \\
\text { group (n=196) }\end{array}$ \\
\hline Total score & Before & $25.12 \pm 3.65 *$ & $60.13 \pm 2.99$ & $61.33 \pm 3.65$ \\
Compulsiveness & After & $25.02 \pm 3.39 *$ & $62.36 \pm 3.25 * *$ & $61.37 \pm 3.74$ \\
Anxiety & Before & $1.71 \pm 1.08 *$ & $4.21 \pm 0.89$ & $4.31 \pm 1.10$ \\
& After & $1.63 \pm 1.08 *$ & $4.51 \pm 1.00$ & $4.35 \pm 0.99$ \\
Depression & Before & $3.47 \pm 1.62 *$ & $8.38 \pm 1.63$ & $8.74 \pm 1.42$ \\
Horror & After & $3.47 \pm 1.41 *$ & $9.05 \pm 1.40 * *$ & $8.44 \pm 1.72$ \\
Psychoticism & Before & $4.00 \pm 1.76 *$ & $9.79 \pm 1.53$ & $9.96 \pm 1.86$ \\
Neurasthenia & After & $4.06 \pm 1.79 *$ & $10.15 \pm 1.53$ & $10.00 \pm 1.63$ \\
Somatization & Before & $2.40 \pm 1.35 *$ & $5.79 \pm 1.32$ & $5.70 \pm 1.38$ \\
& After & $2.25 \pm 1.24 *$ & $5.46 \pm 1.41$ & $5.80 \pm 1.28$ \\
Interpersonal sensitivity & Before & $5.71 \pm 2.01 *$ & $13.18 \pm 1.68$ & $13.56 \pm 1.94$ \\
& After & $5.64 \pm 1.83 *$ & $13.31 \pm 2.12$ & $13.44 \pm 1.85$ \\
Lying & Before & $2.09 \pm 1.17 *$ & $4.95 \pm 1.17$ & $4.88 \pm 1.26$ \\
& After & $2.22 \pm 1.18 *$ & $5.05 \pm 103$ & $5.04 \pm 1.10$ \\
& Before & $3.41 \pm 1.63 *$ & $8.18 \pm 1.54 * *$ & $8.55 \pm 1.58$ \\
& After & $3.39 \pm 1.57 *$ & $8.74 \pm 1.27$ & $8.55 \pm 1.64$ \\
& Before & $2.32 \pm 1.26 *$ & $5.64 \pm 1.37$ & $5.62 \pm 1.30$ \\
& After & $2.35 \pm 1.26 *$ & $6.08 \pm 1.27$ & $5.75 \pm 1.29$ \\
& Before & $3.49 \pm 1.56 *$ & $8.56 \pm 1.57$ & $8.43 \pm 1.66$ \\
& After & $3.33 \pm 1.58^{*}$ & $8.67 \pm 1.56 * *$ & $8.56 \pm 1.64$ \\
\hline
\end{tabular}

Note. * Against the medical group, transporting group, $\mathrm{p}<0.01$; ** Against the transporting group, $\mathrm{p}<0.01$. 
Table 4

Pearson correlation analysis of age-related factors and CMMHS factors (r)

\begin{tabular}{lccccc} 
Items & Age & $\begin{array}{c}\text { Military } \\
\text { service duration }\end{array}$ & $\begin{array}{c}\text { Years of } \\
\text { education }\end{array}$ & Marriage & $\begin{array}{c}\text { Mission } \\
\text { groups }\end{array}$ \\
\hline Total & $0.163 * *$ & $0.168 * *$ & $0.197 * *$ & -0.041 & $0.523 * *$ \\
Compulsive & $0.163 * *$ & $0.165 * *$ & $0.190 * *$ & -0.052 & $0.382 *$ \\
Anxiety & $0.155 * *$ & $0.161 * *$ & $0.169 * *$ & -0.049 & $0.416 * *$ \\
Depression & $0.143 * *$ & $0.150 * *$ & $0.185 * *$ & -0.016 & $0.393 * *$ \\
Horror & $0.138 * *$ & $0.140 * *$ & $0.168 * *$ & -0.034 & $0.455 * *$ \\
Psychosis & $0.129 * *$ & $0.132 * *$ & $0.172 * *$ & -0.024 & $0.469 * *$ \\
Neurasthenia & $0.107 * *$ & $0.109 *$ & $0.123 *$ & -0.050 & $0.315 * *$ \\
Somatization & $0.144 * *$ & $0.148 * *$ & $0.162 * *$ & -0.047 & $0.421 * *$ \\
Interpersonal sensitivity & $0.147 * *$ & $0.152 * *$ & $0.177 * *$ & -0.030 & $0.399 * *$ \\
Lying & $0.182 * *$ & $0.183 *$ & $0.194 * *$ & -0.118 & $0.474 * *$ \\
\hline
\end{tabular}

Note. ${ }^{*} \mathrm{p}<0.05, * * \mathrm{p}<0.01$.

\section{Discussion}

This study has achieved its original purposes. The mental health status of Chinese peacekeepers was worse than average Chinese servicemen. Peacekeepers of different mission groups had different degree of mental damage, and the years of education was the main influence factor for peacekeepers' mental health, whereas age, military service duration as well as military rank were the secondary influence factors.

Participants in peacekeeping operations were frequently exposed to a great variety of stressors, such as hot weather, epidemics, traffic complexity, instability, and potentially traumatic events ${ }^{19-21}$ and even death. There have been 1559 deaths during the UN peacekeeping operation from 1948 to $1998^{22}$. As a result, peacekeepers were faced with great psychological pressure that could lead to psychological disorders ${ }^{23}$. It is no surprise that peacekeepers in this study had worse mental health status than average Chinese servicemen according to Chinese military norm.
Also, peacekeepers might suffer from secondary traumatic stress, which is defined by Figley as the natural consequent behaviors and emotions resulting from knowledge about a traumatizing event experienced by a significant other or from helping or wanting to help a traumatized person ${ }^{24}$. Consequently, the peacekeepers would feel powerlessness, helplessness and anger, and also would vicariously experience the victims' feelings of rage and despair, resulting in secondary traumatic stress disorder ${ }^{25}$.

Factors defining the characteristics of a peacekeeping operation include the degree of chaos and enforcement, length of mission, acceptance by local people and attacks from the local force. However, it seems likely that all peacekeeping operations share some common psychological risk factors and it is useful to identify these in an effort to help prevent and control the untoward effects of stress $^{12}$. In this study, peacekeepers of different mission groups manifested mental damage to different degrees. To be specific, the medical group and transporting group reported worse results than the engineering 
group after the peacekeeping mission, which might result from their different tasks in the mission. The engineering group was responsible for construction of public roads, bridges, airports, or maintaining barracks, etc, which entailed smaller probability of facing fatal danger and less mental burden, whereas the medical group was responsible for healing the sick and wounded and saving the dying. As Liberia was a high-prone area of malaria, typhoid, tuberculosis, hepatitis, AIDS and other endemic, infectious and parasitic diseases, the medical group provided medical support and service not only to the troops, but also to local residents. Thus, they were standing high risks of being infected with sexually transmitted diseases and AIDS. Consequently, mental disorders might be induced by heavy mental burden and long-term anxiety. The transporting group, on the other hand, was responsible for personnel and goods transportation, in addition to some temporary and contingent tasks such as delivery of ballots, etc. Unfamiliarity with the local geography and being alert to local rebels and terrorist attacks in the transporting process rendered them remain under psychological tension, which would further induce some mental disorders. Findings of this study suggest that age, military service duration, years of education, mission groups were related to the mental health of peacekeepers, which was generally consistent with the results of stress research ${ }^{26}$. The peacekeepers who had longer military service or were older in age reported to have more psychological burden in their own situations, such as being married, or had children and elderly parents to take care of. This study also suggested that the years of education was entered into each CMMHS factor regression equation, reflecting different educational levels might relate to the understanding of stressful and traumatic events. In spite of the fact that individuals with higher education level could better cope with unexpected events, officers with generally higher education in this study developed more mental disorders than soldiers due to several factors, such as facing intensive stress derived from fulfilling peacekeeping mission, being responsible for the safety of their subordinates.

Psychological screening of military personnel, which was first used to select pilots and astronauts, began in the 1950s in China. Psychological traits and capabilities were evaluated through psychological measurement and scenario simulation in order to improve the self-protection and military skills. In recent years, increasing attention has been drawn to psychological selection and training of army officers and soldiers. Mental health education and psychological selection for the peacekeepers to Liberia had been conducted prior to departure. This played an important role in preserving psychological health of the peacekeepers. Based upon this study results, none of the peacekeepers showed serious psychological disorders during the peacekeeping mission. But the occurrence of psychological disorders afterwards was still difficult to avoid, and the fact that the medical group and the transporting group reported psychological disorders had proved this point. Therefore, we believed that the test for mental health assessment of soldiers should be taken as routine inspection annually and more frequently for those military personnel ever taking traumatic and stressful missions, with the aim of preserving and maintaining mental health in the army ${ }^{27,28}$. Mental health education and counseling work should be carried out throughout the whole process of peacekeeping. Appropriate number of full-time therapists and psychiatrists should be sent with the troops for psychological intervention, early detection and early intervention in order to improve mental health of soldiers and officers as well as to reduce the incidence of mental disorders, and enhance psychological support for peacekeeping team to fulfill peacekeeping mission successfully. 


\section{Limitations}

There are also some limitations of this study that should be noted. Firstly, inadequate factors had taken into consideration, such as early childhood experiences, negative life events, social support, and personality variances. Secondly, this was a cross-sectional study, lacking evidence of clinical intervention effects, which would require a longitudinal study. Thirdly, there were no servicewomen participating in this study for gender comparison.

\section{Acknowledgments}

All authors wish to thank all the participants.

\section{References}

1. Engel CC, Liu X, McCarthy BD, Miller RF, Ursano R. Relationship of physical symptoms to posttraumatic stress disorder among veterans seeking care for Gulf War-related health concerns. Psychosom Med 2000; 62: 739-745.

2. Hoge CW, Castro CA, Messer SC, McGurk D, Cotting DI, Koffman RL. Combat duty in Iraq and Afghanistan, mental health problems, and barriers to care. N Engl J Med 2004; 351(1): 13-22.

3. Seal KH, Bertenthal D, Miner CR, Sen S, Marmar C. Mental health disorders among 103,788 US veterans returning from Iraq and Afghanistan seen at department of veterans affairs facilities. Arch Intern Med 2007; 167: 476-482.

4. Solomon Z. The impact of posttraumatic stress disorder in military situations. J Clin Psychiatry 2001; 62 (Suppl. 17): 11-15.

5. Stretch R, Bliese P, Marlowe D, Wright M, Knudson K, Hoover C. Psychological health of Gulf War-era military personnel. Mil Med 1996; 161: 257-261.

6. Iversen AC, van Staden L, Hughes JH, Browne T, Hull $\mathrm{L}$, Hall J, et al. The prevalence of common mental disorders and PTSD in the UK military: using data from a clinical interview-based study. BMC Psychiatry 2009; 9(1): 68.

7. Pflanz S. Occupational stress and psychiatric illness in the military: investigation of the relationship between occupational stress and mental illness among military mental health patients. Mil Med 2001; 166(6): 457-462.

8. MacGregor AJ, Shaffer RA, Raman R, Dougherty AL, Lindsay SP, Galarneau MR, et al. Psychological correlates of battle and nonbattle injury among Operation Iraqi Freedom veterans: DTIC Document; 2007.

9. Sayers SL, Farrow VA, Ross J, Oslin DW. Family problems among recently returned military veterans referred for a mental health evaluation. J Clin Psychiatry 2009; 70(2): 163 .

10. Bean MK, Gibson D, Flattery M, Duncan A, Hess M. Psychosocial factors, quality of life, and psychological distress: ethnic differences in patients with heart failure. Prog Cardiovasc Nurs 2009; 24(4): 131-140.

11. Suarez K, Mayer C, Ehlert U, Nater UM. Psychological stress and self-reported functional gastrointestinal disorders. J Nerv Ment Dis 2010; 198(3): 226-229.

12. Shigemura J, Nomura S. Mental health issues of peacekeeping workers. Psychiatry Clin Neurosci 2002; 56(5): 483-491.

13. Hoge CW, Auchterlonie JL, Milliken CS. Mental health problems, use of mental health services, and attrition from military service after returning from deployment to Iraq or Afghanistan. JAMA 2006; 295(9): 1023-1032.

14. Sareen J, Belik S-L, Afifi TO, Asmundson GJG, Cox BJ, Stein MB. Canadian Military Personnel's Population Attributable Fractions of Mental Disorders and Mental Health Service Use Associated With Combat and Peacekeeping Operations. Am J Public Health 2008; 98(12): 2191-2198.

15. Macdonald C, Chamberlain K, Long N, Mirfin K. Stress and mental health status associated with peacekeeping duty for New Zealand Defence Force personnel. Stress Health 1999; 15(4): 235-241.

16. Zhang LY, Wang YZ, Shi JA, Chen C, Li N, Zhang SY. Reliability and validity analysis of the Chinese Military Mental Health Scale. Renmin Junyi 2007; 50(11): 662-663.

17. Chen CX, Xu LL, Zhang LL, Shi JA, Wang JL, You $\mathrm{M}$, et al. CMMHS' application in screening psychological diseases among new military recruits. Renmin Junyi 2010; 53(4): 243-244.

18. Zhang LY, Wang YH, Zhou XD, Lin H, Liu YY, Xu $\mathrm{ZX}$, et al. Establishment of the norm for Chinese Military Personnel Mental Disorder Prediction Scale. Jiefangjun Yixue Zazhi 2011; 36(11): 1220-1222. 
19. Bramsen I, Dirkzwager AJ, Van der Ploegh H. Predeployment personality traits and exposure to trauma as predictors of posttraumatic stress symptoms: A prospective study of former peacekeepers. Am J Psychiatry 2000; 157 : 1115-1119.

20. Gray MJ, Bolton EE, Litz BT. A longitudinal analysis of PTSD symptom course: Delayed-onset PTSD in Somalia peacekeepers. J Consult Clin Psychol 2004; 72: 909-913.

21. Hotopf M, David A, Hull L, Ismail K, Unwin C, Wessely S. The health effects of peacekeeping (Bosnia, 19921996): A cross-sectional study comparison with nondeployed military personnel. Mil Med 2003; 168: 408-413.

22. Seet B, Burnham GM. Fatality trends in United Nations peacekeeping operations, 1948-98. JAMA 2000; 248: 598-603.

23. Shira M, Brett TL, Julie LW, Marie C. The Stressors and Demands of Peacekeeping in Kosovo: Predictors of Mental Health Response. Mil Med 2004; 169(3): 198-206.

24. Figley CR. Compassion Fatigue. Coping with Secondary Traumatic Stress Disorder in Those Who Treat the Traumatized. New York: Brunner/Mazel; 1995.
25. Langholtz HJ. The psychology of peacekeeping. Greenwood Publishing Group; 1998.

26. Luo SQ. The effect of job stress on the military nursing staff emotion. Jiefangjun Hulixue Zazhi 1996; 13: 1-3.

27. Elhai JD, Don Richardson J, Pedlar DJ. Predictors of general medical and psychological treatment use among a national sample of peacekeeping veterans with health problems. J Anxiety Disord 2007; 21(4): 580-589.

28. Susan LR. Contemporary Treatments for Psychological Trauma From the Perspective of Peacekeepers. Can J Nurs Res 2009; 41(2): 114-128.

Corresponding author:

Dr. Li-yi Zhang

Prevention and Treatment Center of Psychological Diseases, No. 102

Hospital of Chinese People's Liberation Army

North Peace Road 55

Changzhou 213003

Jiangsu, P.R. China

E-mail: zly102@126.com 